Ssciendo

\title{
Discussion Note \\ Whyte on desire fulfilment conditions: a simple problem
}

Jake Chandler

King's College London

Disputatio Vol. 2, No. 21

November 2006

DOI: $10.2478 /$ disp-2006-0014

ISSN: 0873-626X

(C) 2006 Chandler. Creative Commons Attribution-NonCommercial-NoDerivs 3.0 License 


\title{
Discussion note
}

\section{Whyte on desire fulfilment conditions: a simple problem}

\author{
Jake Chandler \\ King's College London
}

\begin{abstract}
According to Jamie Whyte, the proper assignment of fulfilment conditions to an agent's set of desires proceeds in three steps. First, one identifies various desire extinction and behavioural reinforcement conditions to obtain the fulfilment conditions of a certain subset of the agent's desires. With these fulfilment conditions in hand, one then appeals to a principle connecting desire fulfilment conditions with belief truth conditions to obtain the truth conditions of a number of the agent's beliefs. Finally, one uses these belief truth conditions to generate, via a third principle, the fulfilment conditions for the remaining desires. There is, however, a very straightforward reason why this strategy cannot yield the required results.
\end{abstract}

In 'The Normal Rewards of Success' Jamie Whyte offered an extremely original disjunctive account of the fulfilment conditions of desires. He suggested that, for a number of desires ('basic' desires), fulfilment conditions can be captured in terms of desire extinction and behavioural reinforcement conditions. For those desires whose fulfilment conditions resist this kind of analysis ('non-basic' desires), he proposed a second strategy: fulfilment conditions are analysed in terms of the truth conditions of various beliefs, which themselves are analysed in terms of the fulfilment conditions of various basic desires. In what follows, I point out a simple problem with Whyte's strategy for assigning content to 'non-basic' desires.

According to Whyte, we can apply, for a number of desires, what one might call a 'reinforcement / extinction' theory of desire contents. This theory draws on two widely observed features of the psychology of desire: (1) the occurrence of a desire D's fulfilment condition typically leads to its extinction and (2) the satisfaction of a 
desire $D$ by means of an action $A$ commonly reinforces a disposition to subsequently carry out $A$ upon holding $D$. Although no formal version of his account is presented, it would appear that the idea is somewhat like the following:

Des $_{1} \quad G$ is the satisfaction condition of desire $D$ iff (i) there is an action $A$ such that $D$ causes $A, A$ causes $G$ and $G$ causes $\sim D$, and (ii) the occurrence of $\sim D$ raises the probability $D$ 's causing $A$ in the future.

The idea is straightforward. According to $\mathrm{Des}_{1}$, when I want chocolate, it is chocolate that I want and not anything else because when, for instance, upon desiring chocolate, I go to the fridge and obtain some chocolate, it is my getting chocolate (and not anything else) that both (a) quenches my desire for chocolate and (b) will thereby make me more likely to go to the fridge next time I am in that state. ${ }^{1}$

Whatever the flaws and merits of this approach, one thing is certain: as Whyte himself points out, there are a number of desires whose fulfilment conditions cannot possibly be given by $\operatorname{Des}_{1}$. These include notably one's desire to be cremated or again one's desire for the prosperity of one's distant descendants, whose satisfaction in incompatible with the very existence of the desirer. ${ }^{2}$ In order to deal with these recalcitrant desires, Whyte introduces a second contentdetermining principle:

$\mathrm{Des}_{2}$ 'A desire's fulfilment condition is that condition which is guaranteed to result from any action caused by that desire, if the beliefs with which it combines to cause the action are true.'

\footnotetext{
${ }^{1}$ Des $_{1}$ can be seen as an attempt to improve on theories that merely appeal to the notion of desire extinction, such as the one once offered by Russell 1921. These theories notably face the problem of accounting for the content of those desires that are extinguished by states of affairs, which intuitively should not figure in their fulfilment conditions. Indeed, a desire for food can be extinguished by a glass of sour milk as can a burning ambition by a lifetime of failure. However, if a desire for food might well be extinguished by a pint of sour milk, it will not be so in such a way as to encourage one to repeat the experience next time one is hungry. Dretske 1988 offers an account similar to Des $_{1}$.

${ }^{2}$ See also Papineau 1993, chapter 3.
} 
Des $_{2}$ makes desire fulfilment conditions hinge on belief truth conditions. Now belief truth conditions are given, according to Whyte, by the following principle:

Bel A belief B's truth condition is the possible state of affairs which would be sufficient for the fulfilment of any desire $D$ by the action $A$ which $B$ and $D$ would combine to cause (Whyte 1990).

According to Whyte then, for those desires whose fulfilment conditions are not given by $\operatorname{Des}_{1}$, content-assignment is a three-stage process: (i) Des ${ }_{1}$ gives us the content for a certain number of desires, (ii) from the content of these desires, by applying Bel, we can obtain the truth conditions for a certain number of beliefs, (iii) from there, by applying $\operatorname{Des}_{2}$, we obtain the fulfilment conditions of the remaining desires:

Suppose something else, independent of $\left[\mathrm{Des}_{2}\right]$ gives the content of some desire $D$. Then [Bel] would give the content of those beliefs with which $D$ would combine to cause actions. [Des $\left.{ }_{2}\right]$ would then invoke the contents of those beliefs to give the contents of the other desires with which they would combine. And so on... [Bel] and $\left[\mathrm{Des}_{2}\right]$ may not on their own give the contents of desires and beliefs; but is a few desires get their content in some other way, [Bel] and $\left[\mathrm{Des}_{2}\right]$ may be able to give content to the rest. (Whyte 1991:65-66)

But Whyte's scheme simply cannot work the way he suggests. Say we have used Des 1 to get the satisfaction conditions for some desire $D$. Now, following Whyte's recommendations, we use Bel to obtain the truth conditions for the beliefs with which $D$ can combine to cause actions. At this point, we have two possible scenarios: (1) the relevant beliefs do not cause actions in combination with any further desires, (2) the relevant beliefs do cause actions in combination with further desires. If (1) is the case, having used Bel to obtain the truth conditions of the beliefs, we cannot use $\mathrm{Des}_{2}$ to get the satisfaction conditions of any further desires: there are no further desires which are appropriately connected. But if (2) is the case, we could not have used Bel to get the truth conditions of those beliefs in the first place, given the fact that we merely have the satisfaction conditions of $D$ : to use Bel we need the satisfaction conditions of all the desires with 
which these beliefs could combine to cause actions, not just those of $D$. The fulfilment conditions of Whyte's 'non-basic' desires remain unaccounted for. ${ }^{3}$

Jake Chandler

King's College London

Strand, London WC2R 2LS, UK

jake.chandler@kcl.ac.uk

\section{References}

Dretske, Fred. 1988. Explaining Behavior. Cambridge MA: MIT Press.

Papineau, David. 1993. Philosophical Naturalism. Oxford: Blackwell.

Russell, Bertrand. 1921. The Analysis of Mind. London: George Allen \& Unwin.

Whyte, Jamie. 1990. Success Semantics. Analysis 50: 149-157.

Whyte, Jamie. 1991. The Normal Rewards of Success. Analysis 51:65-73.

${ }^{3}$ In addition to the problem just raised one might also want to point out the dubious plausibility of $\mathrm{Des}_{2}$ itself: if the truth of one's beliefs is indeed sufficient for one's actions to bring about the states of affairs that one desires, it is surely, at least occasionally, sufficient for one's actions to bring about a whole lot more than what one cares about. 